\title{
The minipig as a potential model for pedicle screw fixation: morphometry and mechanics
}

\author{
Robert A. Harper ${ }^{1}$, Ferris M. Pfeiffer ${ }^{2}$ and Theodore J. Choma ${ }^{3 *}$
}

\begin{abstract}
Background: While there are several different animal models for use in the characterization of spinal fixation, none have emerged as a definitive model for comparative studies in spinal fixation methods. The purpose of this study is to establish morphometric data of porcine vertebrae and to characterize the feasibility of pedicle screw fixation in porcine spines for potential comparative human study.

Methods: Four spines from 45 to $50 \mathrm{~kg}$ Hanford minipigs were cleaned of soft tissue and analyzed by computed tomography and dual-energy $\mathrm{x}$-ray absorptiometry. Two $5 \times 30-\mathrm{mm}$ pedicle screws were placed in each vertebra and tested to failure using a combined moment-load protocol.

Results: Pedicle widths were measured from L6-T5. Widths ranged from $7.15 \mathrm{~mm}$ (T6) to $9.24 \mathrm{~mm}$ (T14). Posterior cortex to anterior cortex depth ranged from 25.9 to $32.6 \mathrm{~mm}$. Mean bone mineral density was $1.0665 \mathrm{~g} / \mathrm{cm}^{2}$ (range 1.139-1.016). Force-to-failure demonstrated mean $1171.40 \mathrm{~N}$ (+ 115.34).

Conclusion: Our baseline morphometric and compositional data demonstrate that porcine vertebrae can serve as a useful model for comparative studies due to their similar pedicle widths and bone mineral density to the human vertebra. This biomechanical data could provide a baseline comparison for future studies. This study also suggests that the minipig could be a suitable model for comparative studies due to similarities in pedicle width and bone mineral density to the human vertebrae.
\end{abstract}

Keywords: Bone mineral density, Pedicle screw, Morphometric characterization, Spinal fixation, Biomechanical analysis, Porcine vertebra model

\section{Introduction}

There is no generally accepted single animal model for spinal fixation methods. Several different study animals have been used in the characterization of spinal fixation, including sheep [1, 2], cow [3-7], and pig [8], but none has emerged as a gold standard for comparative study. The minipig is an established research animal for comparative human studies in areas as diverse as dermatology [9], endocrinology/diabetes [10], cardiology [11], immunology [12], pharmacology [13], and toxicology [14] due to similarities to human systems. The porcine

\footnotetext{
* Correspondence: chomat@health.missouri.edu

This study was presented as a poster at the One AO Meeting in Las Vegas, NV, in February 2015.

${ }^{3}$ Department of Orthopaedic Surgery, University of Missouri, 1100 Virginia

Avenue DC953.00, Columbia, MO 65212, USA

Full list of author information is available at the end of the article
}

spine may also be an important model for human spinal fixation and instrumentation techniques. McClain et al. found key similarities of porcine to the human vertebra in their analysis of the morphometry of the L4 vertebra in several large animal species [15]. Dath et al. compiled a database of porcine vertebral measurements-including pedicle width, end plate size, and spinous process size-but limited their measurements to lumbar vertebrae [16] and did not include an important measurement for spinal instrumentation: the screw path length from posterior to anterior cortex, referred to by Krag et al. as "chord length" [17]. Characterization of pedicle isthmus width and chord length for the porcine thoracic spine has not been previously published. As such, comprehensive characterization of porcine vertebral morphometry is necessary for effective human comparison. 
If the minipig is to be a useful model for spinal fixation methods, measurements of bone mineral density (BMD) and pedicle screw force to failure in normal porcine spines would be necessary for baseline comparison to future fixation experiments. This leads to the current investigation into the feasibility of using the minipig to assess spinal fixation strategies.

Many previous authors assessing the biomechanics of pedicle screw fixation used pure axial pullout to assess screw interface, but there are many questions about the clinical validity of these simple loading schemes. We have described previously a complex test method that simulates complex in vivo loading for pedicle screw fixation analysis [18].

The goals of this pilot study are twofold: to establish morphometric and compositional data of the minipig thoracic and lumbar vertebrae for potential comparative human study and to characterize the feasibility of pedicle screw fixation in normal minipig spines for comparison with future studies.

\section{Materials and methods Morphometry}

Four porcine spines, cleaned of soft tissue, were procured from the Sinclair Research Laboratory Farm (Auxvasse, MO). The spines were from adult male Hanford miniature swine aged 14 to 15 months, weighing 45 to $50 \mathrm{~kg}$, which were sacrificed for reasons unrelated to this particular study. The lumbar regions of the whole vertebral columns were scanned with dual-energy $x$-ray absorptiometry (DXA) (Hologic, Bedford, MA) to determine BMD. Specimens were then imaged with quantitative computerized tomography (Toshiba American Medical Systems, Tustin, CA) to generate vertebral morphometry. Using Amira (Visage Imaging $\mathrm{GmbH}$, Berlin, Germany) visualization software, transverse pedicle isthmus width and distance from posterior to anterior cortex along the pedicle axis (AC depth) were measured for each vertebra.

\section{Screw purchase}

The vertebrae were separated from connective tissue for instrumentation. A small starting hole (approximately 3 $\mathrm{mm}$ ) in the posterior cortex was created on each side with a rongeur, exposing cancellous bone. A pilot hole was made with a tapered Lenke probe. A titanium $5 \times$ 30-mm (Synthes USS) fixed pedicle screw (Synthes AG, West Chester, PA) was inserted into each pilot hole (Fig. 1) and a $5.5 \times 65-\mathrm{mm}$ titanium rod was inserted into each screw head and secured with an endcap and locking nut, tightened to the manufacturer's recommended torque.

The inferior portion of the rod was held securely in an angle vise, $\Theta=45$, and stabilized superiorly to prevent

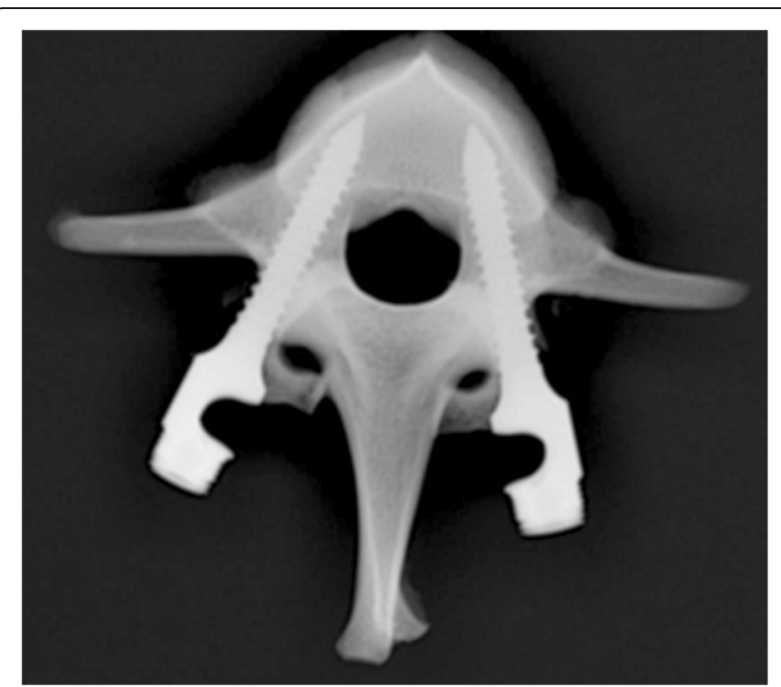

Fig. 1 Radiograph of the lumbar vertebra with pedicle screws implanted bilaterally

bending. The specimen was held in a custom apparatus which clamped the vertebral body similar to the complex loading previously described (Fig. 2) [1]. The apparatus was attached to a $46.6-\mathrm{cm}$ long pushrod. Loading tests were performed using a servo-hydraulic test machine (Instron 8821S, Norwood, MA). Force was applied through the pushrod at a displacement controlled rate of $5 \mathrm{~mm} / \mathrm{s}$ until ultimate failure, defined as either fracture of the pedicle or mechanical failure (fracture of plastic deformation) of the screw.

\section{Results}

\section{Morphometry}

Mean BMD across all specimens was $1.067 \mathrm{~g} / \mathrm{cm}^{2}$ $\left( \pm .0462 \mathrm{~g} / \mathrm{cm}^{2}\right)$ (Table 1). The widest pedicle isthmus was seen at T14 with a mean value of $9.24 \mathrm{~mm}$ (range 7.45 to $10.47 \mathrm{~mm}$ ). The narrowest pedicle isthmus was seen at $\mathrm{T} 5$ with a mean value of $7.16 \mathrm{~mm}$ (range 5.56 to $8.59 \mathrm{~mm}$ ) (Fig. 3). The longest AC depth was measured at L5 with a mean value of $32.61 \mathrm{~mm}$ (range 29.44 to $35.5 \mathrm{~mm}$ ). The shortest was measured at T6 with a mean value of $25.96 \mathrm{~mm}$ (range 24.21 to $28.84 \mathrm{~mm}$ ) (Fig. 4).

\section{Fixation biomechanics}

In each case, the failure loads were so high that the screws bent either just previous to or simultaneously with screw failure. Mean force to failure was $1171.40 \mathrm{~N}$ ( \pm 115.43$)$ (Table 2). Once we recognized how constant this failure load and mechanism was, we discontinued loading to failure. The consistency of the failure data made it necessary to test only four vertebrae for a total of eight measurements. 


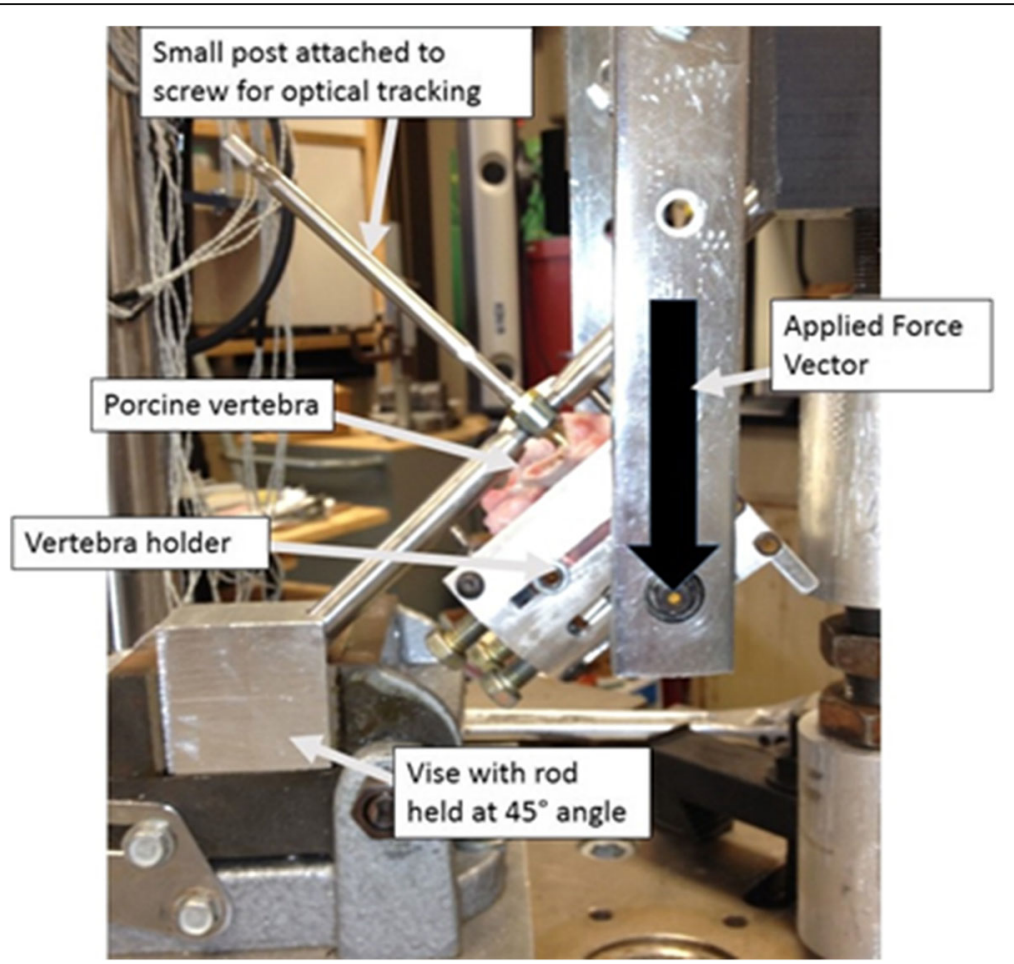

Fig. 2 Vertebra with implanted pedicle screw clamped into the apparatus. A titanium rod is inserted into the screw and is secured inferiorly by a vise

\section{Discussion}

The mean and standard deviation of BMD values for young normal adults have been previously published in the literature. Simmons et al. reported the adult human reference BMD for each of the principal DXA manufacturers. Reported values were as follows: Hologic $1.079 \mathrm{~g} / \mathrm{cm}^{2}$ $(+0.110)$, Lunar $1.200 \mathrm{~g} / \mathrm{cm}^{2}(+0.120)$, Norland Europe $1.085 \mathrm{~g} / \mathrm{cm}^{2}(+0.115)$, and Norland US $1.164 \mathrm{~g} / \mathrm{cm}^{2}$ $(+0.162)$ [19]. The adult Hanford minipig in this study demonstrated a mean BMD of $1.067 \mathrm{~g} / \mathrm{cm}^{2}$ $\left( \pm .0462 \mathrm{~g} / \mathrm{cm}^{2}\right)$, comparable to adult human reference BMD reported in the literature. This similarity is a favorable factor in determining whether the minipig would be a suitable study model. Our findings also agree with others who have investigated porcine BMD.

Lee et al. found similar BMD to our study in their in vitro porcine model of osteoporosis with a mean BMD of $1.189 \pm .05 \mathrm{~g} / \mathrm{cm}^{2}$ [20]. Mitchell et al. reported a mean BMD measurement of $1.057 \mathrm{~g} / \mathrm{cm}^{2}$ in live,

Table 1 Specimen bone mineral density

\begin{tabular}{ll}
\hline Specimen & BMD g/cm \\
\hline Spine 1 & 1.139 \\
Spine 2 & 1.016 \\
Spine 3 & 1.04 \\
Spine 4 & 1.071 \\
\hline
\end{tabular}

anesthetized, $60 \mathrm{~kg}$ pigs [21]. The similarity to the present study helped to mitigate the concern that in vitro DXA measurements of porcine spines cleaned of soft tissue would not accurately represent in vivo BMD values. Although we did not study mineralization, Moskilde et al. found that the porcine skeletal system contains lamellar bone and undergoes trabecular and cortical remodeling in a similar fashion to humans [22]. In a separate study, Moskilde et al. were able to create osteoporosis in the minipig spine through ovariectomy, calcium restriction, and glucocorticoid administration [23]. This raises the prospect that future spinal fixation studies employing Moskilde's osteoporosis model, compared with the data in our study may elucidate effective strategies for spinal fixation methods in osteoporotic spines. Our BMD analysis allows us to infer that the porcine spine may be a suitable comparison to the human spine.

Along the same lines, some animal model research has focused on coated pedicle screws that may improve fixation at the bone-implant interface [6, 24-26]. Ohe et al. recently implanted 3 types of screws-untreated, sandblasted, and hydroxyapatite (HA) - into 8 Clawn miniature pigs in a 24-week study (6 osteoporosis group, 2 control). They found that the HA coating may reduce the level of loosening of the screws but that absence of increased BMD around the screws was still problematic [26]. 


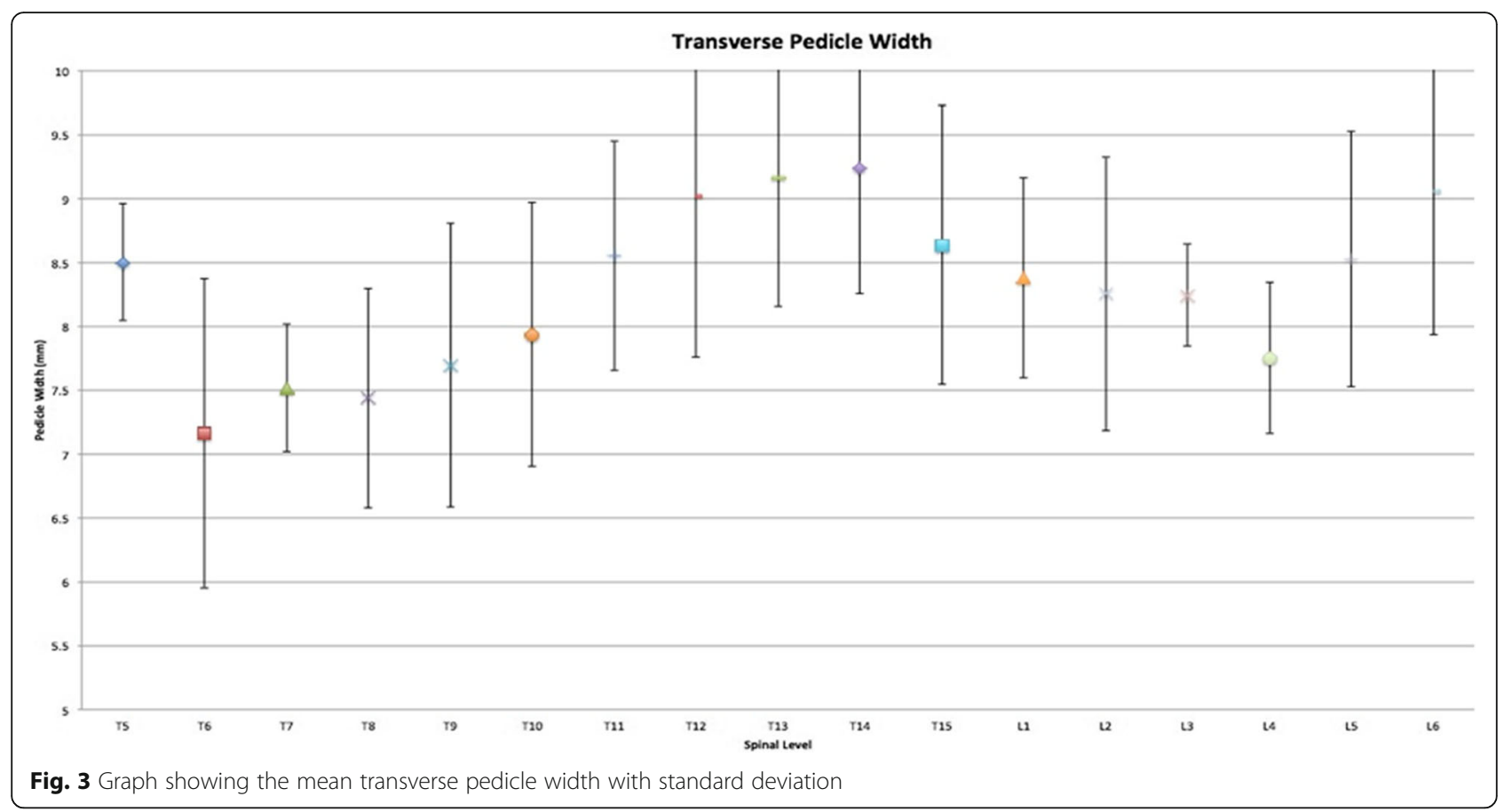

The pedicle morphometry data in our study demonstrate that instrumentation with adult human-sized pedicle screws is possible. Lumbar and thoracic vertebrae had similar pedicle isthmus widths to the human widths measured by Zindrick et al. [27]. Mid to upper thoracic pedicles in our specimens demonstrated a perforated pedicle, in which there was a lateral foramen that bisected the pedicle (Fig. 5). This aspect of the spines may preclude pedicle screw instrumentation of that region. Distance from the posterior to the anterior cortex (AC depth) was considerably shorter than that measured in humans by Zindrick et al. [27]. However, most of the lumbar and lower thoracic vertebrae had AC depths greater than $30 \mathrm{~mm}$, which accepted a $5 \times 30-\mathrm{mm}$ screw

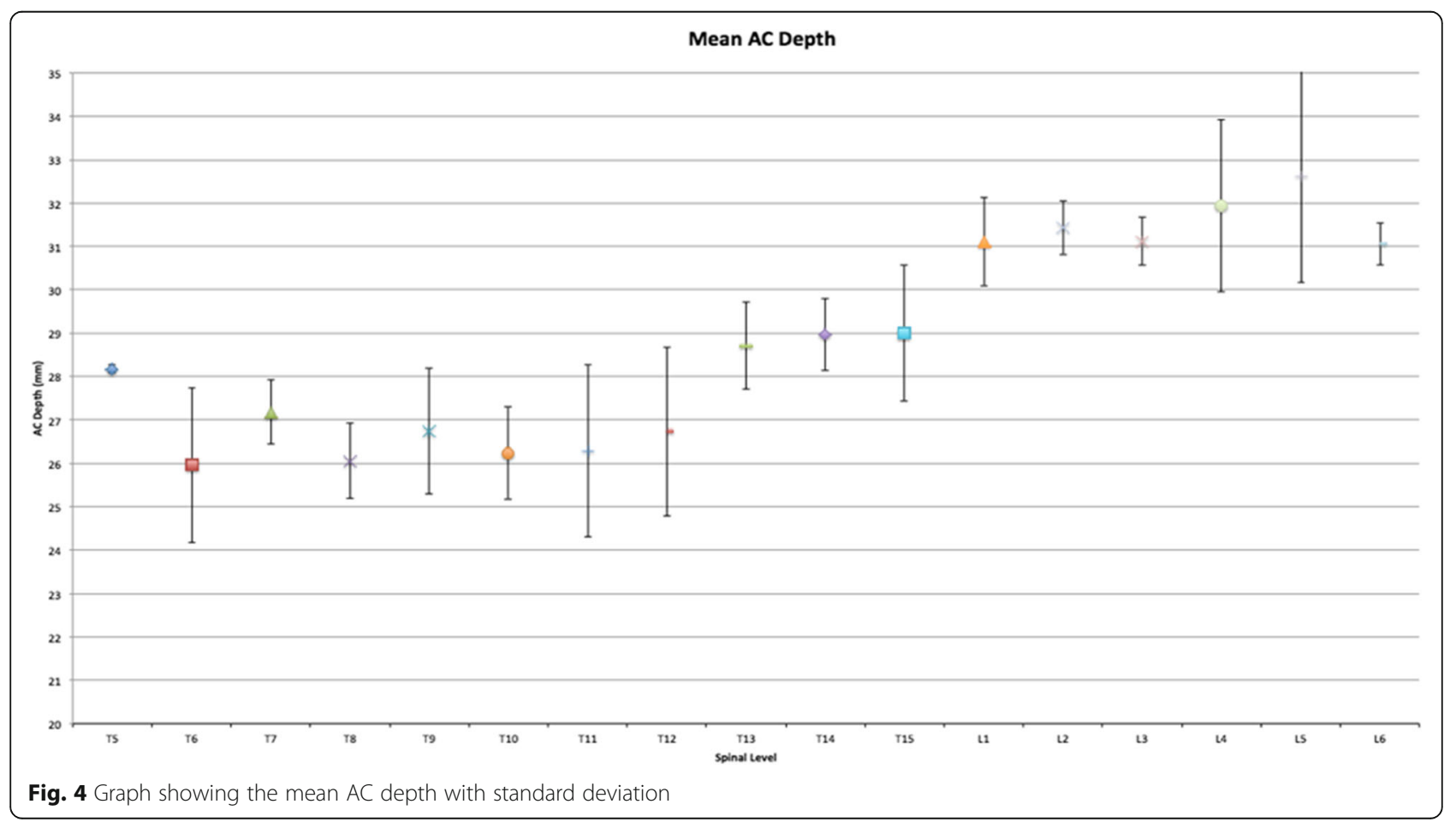


Table 2 Pedicle screw force to failure specimen bone mineral density

\begin{tabular}{ll}
\hline Vertebra & Screw force to failure $(N)$ \\
\hline L2 left & 1124.58 \\
L2 right & 1208.39 \\
L3 left & 1141.36 \\
L3 right & 1039.12 \\
L4 left & 1405.33 \\
L4 right & 1050.24 \\
L5 left & 1202.58 \\
L5 right & 1199.57 \\
\hline
\end{tabular}

in this study, without ventral perforation. Mid- to upper thoracic vertebrae had AC depths shorter than $30 \mathrm{~mm}$, making pedicle screw instrumentation less feasible without custom-made short screws.

The vertebrae in our study demonstrated an extremely high force to failure. In this pilot study, the titanium rod would often bend before screw failure. By providing enhanced rod reinforcement and defining failure as the relative movement of the screw suggesting displacement within the trabecular meshwork, we were able to achieve consistent force to failure data. Aerssens et al. found that porcine bone had a higher bone mineral content and higher yield stress necessary for trabecular compression than commonly seen in humans [28]. In a human-toporcine comparison of bone microarchitecture, the porcine spine was shown to have thicker trabeculae [11]. This may require further study to fully characterize and draw comparative conclusions to adult human vertebral bone strength.

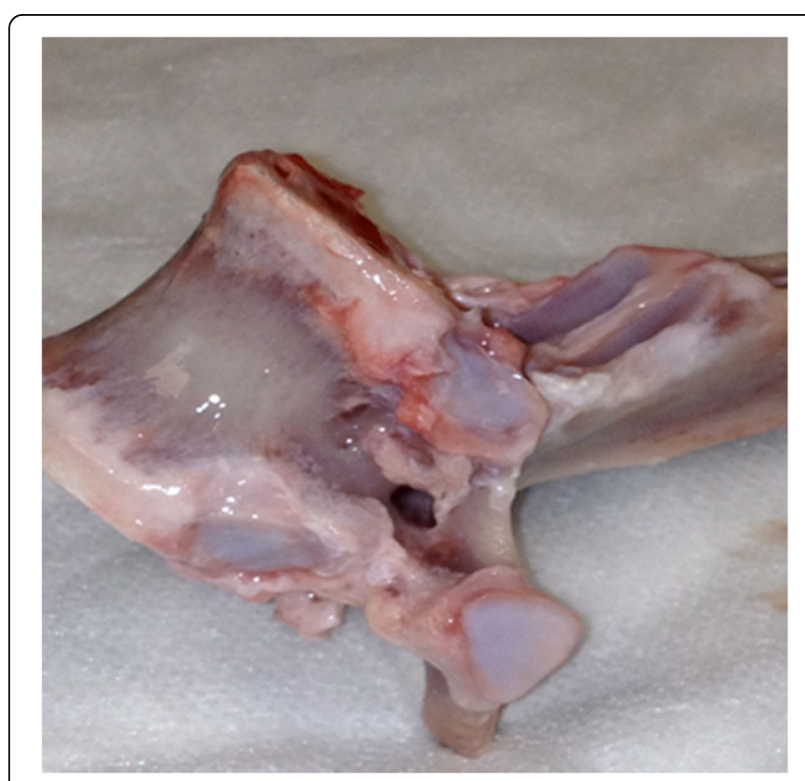

Fig. 5 Thoracic vertebra with lateral foramen bisecting the pedicle
Our study has several limitations. The high failure loads exhibited in this study were quite notable, raising the question of whether mechanical findings in the healthy minipig would be directly predictive of implant behavior in humans. These data could be the result of differences in the microarchitecture of the porcine spine or a function of the smaller vertebral bodies. However, even if the force to fixation failure is consistently higher than in the adult human, the relative patterns of fixation between healthy bone and induced osteopenia/osteoporosis may still be very instructive. Another limitation is the shorter $\mathrm{AC}$ depth in the mid to upper thoracic vertebrae which precluded pedicle screw instrumentation as our smallest available screw length was $30 \mathrm{~mm}$. Since porcine spines contain up to 15 thoracic and up to 6 lumbar vertebrae, we found 8 to 10 vertebrae from each spine in our study that would accommodate a pedicle screw, more than adequate to conduct studies in spinal fixation. Given the morphometric variation based on spinal levels, it would seem very important that any future studies specify exactly which porcine vertebrae would be used in order to draw conclusions about spinal fixation in humans. A final limitation to this pilot study was the small sample size of four porcine spines. Although our failure data and morphometric analysis in this pilot generated consistent measurements, a larger study with additional specimens may provide additional detail beyond our initial characterization.

\section{Conclusions}

This pilot study suggests that the minipig could be a suitable model for comparative studies due to similarities in pedicle width and BMD to the human vertebrae. These measurements and biomechanical data could provide a useful reference for future studies of spinal fixation methods considering the minipig as a model.

\section{Abbreviations \\ AC: Anterior cortex; BMD: Bone mineral density; DXA: Dual-energy x-ray absorptiometry; HA: Hydroxyapatite}

Acknowledgements

This study was presented as a poster at the One AO Meeting in Las Vegas, NV, in February 2015.

Authors' contributions

RAH and TJC drafted the manuscript. FMP and TJC carried out the biomechanical analysis and measurements. RAH, FMP, and TJC reviewed and accomplished the statistical analyses. TJC and FMP made substantial contributions in the conception of the study and supervised the conduction of it. RAH, FMP, and TJC revised the manuscript and approved the final manuscript.

\section{Funding}

No external funding source was used in the execution of this study.

Availability of data and materials

All the available data analyzed during this study are included in this published article. 


\section{Ethics approval and consent to participate}

This study was conducted on four cadaver porcine spines (adult male Hanford miniature swine). Our institution does not require approval on human or animal cadaver specimen studies.

\section{Consent for publication}

Not applicable.

\section{Competing interests}

The authors declare that they have no competing interests.

\section{Author details}

${ }^{1}$ Department of Orthopedic Surgery, University of California-Davis, 4860 Y Street, Sacramento, CA 95817, USA. ²Department of Biological Engineering, University of Missouri, 247 Ag Engineering Building, Columbia, MO 65211 USA. ${ }^{3}$ Department of Orthopaedic Surgery, University of Missouri, 1100 Virginia Avenue DC953.00, Columbia, MO 65212, USA

Received: 13 February 2019 Accepted: 25 July 2019

Published online: 05 August 2019

\section{References}

1. Kanayama M, Cunningham BW, Weis JC, Parker LM, Kaneda K, McAfee PC. Maturation of the posterolateral spinal fusion and its effect on load-sharing of spinal instrumentation. An in vivo sheep model. J Bone Joint Surg Am. 1997;79:1710-20

2. Yaman O, Demir T, Arslan AK, Iyidiker MA, Tolunay T, Camuscu N, et al. The comparison of pullout strengths of various screw designs on synthetic foams and ovine vertebrae. Turk Neurosurg. 2015;25:532-8.

3. Demir T. A new alternative to expandable pedicle screws: expandable polyether-ether-ketone shell. Proc IMechE Part H: J Engineering in Medicine. 2015;229:386-94

4. Tolunay T, Başgül C, Demir T, Yaman ME, Arslan AK. Pullout performance comparison of pedicle screws based on cement application and design parameters. Proc IMechE Part H: J Engineering in Medicine. 2015;229:786-93.

5. Aycan MF, Yaman ME, Usta Y, Demir T, Tolunay T. Investigation of toggling effect on pullout performance of pedicle screws. Proc IMechE Part H: J Engineering in Medicine. 2018;232:395-402.

6. Yildirim OS, Aksakal B, Hanyaloglu SC, Erdogan F, Okur A. Hydroxyapatite dip coated and uncoated titanium poly-axial pedicle screws: an in vivo bovine model. Spine (Phila Pa 1976). 2006;31:E215-20.

7. Thomas A, Kepler CK, Meyers K, Green DW, Wright TM, Rawlins BA. The effect of sacral decortication on lumbosacral fixation in a calf spine model. Spine (Phila Pa 1976). 2011:36:E388-92.

8. Zou X, Li H, Teng X, Xue Q, Eqund N, Lind M, et al. Pedicle screw fixation enhances anterior lumbar interbody fusion with porous tantalum cages: an experimental study in pigs. Spine (Phila Pa 1976). 2005;30:E392-9.

9. Sambuco CP. Miniature swine as an animal model in photodermatology: factors influencing sunburn cell formation. Photodermatol. 1985;2:144-50.

10. Strauss A, Moskalenko V, Tiurbe C, Chodnevskaja I, Timm S, Wiegering VA, et al. Goettingen Minipigs (GMP): comparison of two different models for inducing diabetes. Diabetol Metab Syndr. 2012;4:7.

11. Grehan JF, Hilbert SL, Ferrans VJ, Droel JS, Salerno CT, Bianco RW. Development and evaluation of a swine model to assess the preclinical safety of mechanical heart valves. J Heart Valve Dis. 2000;9:710-9 discussion 719-20.

12. Rothkotter HJ, Sowa E, Pabst R. The pig as a model of developmental immunology. Hum Exp Toxicol. 2002;21:533-6.

13. Anzenbacherová E, Anzenbacher P, Svoboda Z, Ulrichová J, Kvetina J, Zoulová J, et al. Minipig as a model for drug metabolism in man: comparison of in vitro and in vivo metabolism of propafenone. Biomed Pap Med Fac Univ Palacky Olomouc Czech Repub. 2003;147:155-9.

14. Swindle MM, Makin A, Herron AJ, Clubb FJ Jr, Frazier KS. Swine as models in biomedical research and toxicology testing. Vet Pathol. 2012:49:344-56.

15. McLain RF, Yerby SA, Moseley TA. Comparative morphometry of $L 4$ vertebrae: comparison of large animal models for the human lumbar spine. Spine (Phila Pa 1976). 2002;27:E200-6

16. Dath R, Ebinesan AD, Porter KM, Miles AW. Anatomical measurements of porcine lumbar vertebrae. Clin Biomech (Bristol, Avon). 2007;22:607-13.
17. Krag MH, Weaver $\mathrm{DL}$, Beynnon BD, Haugh LD. Morphometry of the thoracic and lumbar spine related to transpedicular screw placement for surgical spinal fixation. Spine (Phila Pa 1976). 1988;13:27-32.

18. Choma TJ, Frevert WF, Carson WL, Waters NP, Pfeiffer FM. Biomechanical analysis of pedicle screws in osteoporotic bone with bioactive cement augmentation using simulated in vivo multicomponent loading. Spine (Phila Pa 1976). 2011;36:454-62.

19. Simmons A, Simpson DE, O'Doherty MJ, Barrington S, Coakley AJ. The effects of standardization and reference values on patient classification for spine and femur dual-energy X-ray absorptiometry. Osteoporos Int. 1997;7:200-6

20. Lee CY, Chan SH, Lai HY, Lee ST. A method to develop an in vitro osteoporosis model of porcine vertebrae: histological and biomechanical study. J Neurosurg Spine. 2011;14:789-98

21. Mitchell AD, Scholz AM, Pursel VG. Total body and regional measurements of bone mineral content and bone mineral density in pigs by dual energy X-ray absorptiometry. J Anim Sci. 2001;79:2594-604.

22. Mosekilde L, Kragstrup J, Richards A. Compressive strength, ash weight, and volume of vertebral trabecular bone in experimental fluorosis in pigs. Calcif Tissue Int. 1987:40:318-22.

23. Moskilde L, Weisbrode SE, Safron JA, Stills HF, Jankowsky ML, Ebert DC, et al. Calcium restricted ovariectomized Sinclair S-1 minipigs: an animal model of osteopenia and trabecular plate perforation. Bone. 1993;14:379-82.

24. Aldini NN, Fini M, Giavaresi G, Giardino R, Greggi T, Parisini P. Pedicular fixation in the osteoporotic spine: a pilot in vivo study on long-term ovariectomized sheep. J Orthop Res. 2002;20:1217-24.

25. Hasegawa T, Inufusa A, Imai Y, Mikawa Y, Lim TH, An HS. Hydroxapatite-coating of pedicle screws improves resistance against pull-out force in the osteoporotic canine lumbar spine model: a pilot study. Spine J. 2005;5:239-43.

26. Ohe M, Moridaira H, Inami S, Takeuchi D, Nohara Y, Taneichi H. Pedicle screws with a thin hydroxyapatite coating for improving fixation at the bone-implant interface in the osteoporotic spine: experimental study in a porcine model. J Neurosurg Spine. 2018;30:1-9.

27. Zindrick MR, Wiltse LL, Doornik A, Widell EH, Knight GW, Patwardhan AG, et al. Analysis of the morphometric characteristics of the thoracic and lumbar pedicles. Spine (Phila Pa 1976). 1987:12:160-6.

28. Aerssens J, Boonen S, Lowet G, Dequeker J. Interspecies differences in bone composition, density, and quality: potential implications for in vivo bone research. Endocrinology. 1998;139:663-70.

\section{Publisher's Note}

Springer Nature remains neutral with regard to jurisdictional claims in published maps and institutional affiliations.

Ready to submit your research? Choose BMC and benefit from:

- fast, convenient online submission

- thorough peer review by experienced researchers in your field

- rapid publication on acceptance

- support for research data, including large and complex data types

- gold Open Access which fosters wider collaboration and increased citations

- maximum visibility for your research: over $100 \mathrm{M}$ website views per year

At BMC, research is always in progress.

Learn more biomedcentral.com/submission 